\title{
Age of donor alters the effect of cyclic hydrostatic pressure on production by human macrophages and osteoblasts of sRANKL, OPG and RANK
}

\author{
CE Evans*1, S Mylchreest ${ }^{1}$ and JG Andrew ${ }^{2}$
}

Address: ${ }^{1}$ Laboratory \& Regenerative Medicine, Stopford Building, The Medical School, University of Manchester, Oxford Road, Manchester M13 9PT, UK and 2 Department of Orthopaedic Surgery, Ysbyty Gwynedd, Bangor, LL57 2PW, UK

Email: CE Evans* - carol.evans@man.ac.uk; S Mylchreest - sarah.lewis@man.ac.uk; JG Andrew - Glynne.Andrew@nww-tr.wales.nhs.uk

* Corresponding author

Published: 06 March 2006

BMC Musculoskeletal Disorders 2006, 7:21 doi:10.1 186/147|-2474-7-21

Received: II July 2005

Accepted: 06 March 2006

This article is available from: http://www.biomedcentral.com/I47/-2474/7/2 I

(C) 2006 Evans et al; licensee BioMed Central Ltd.

This is an Open Access article distributed under the terms of the Creative Commons Attribution License (http://creativecommons.org/licenses/by/2.0), which permits unrestricted use, distribution, and reproduction in any medium, provided the original work is properly cited.

\begin{abstract}
Background: Cyclic hydrostatic pressure within bone has been proposed both as a stimulus of aseptic implant loosening and associated bone resorption and of bone formation. We showed previously that cyclical hydrostatic pressure influenced macrophage synthesis of several factors linked to osteoclastogenesis. The osteoprotegerin/soluble receptor activator of NF-kappa $\beta$ ligand /receptor activator of NF-kappa $\beta$ (OPG/ RANKL/ RANK) triumvirate has been implicated in control of bone resorption under various circumstances. We studied whether cyclical pressure might affect bone turnover via effects on OPG/ sRANKL/ RANK.
\end{abstract}

Methods: In this study, cultures of human osteoblasts or macrophages (supplemented with osteoclastogenic factors) or co-cultures of macrophages and osteoblasts (from the same donor), were subjected to cyclic hydrostatic pressure. Secretion of OPG and sRANKL was assayed in the culture media and the cells were stained for RANK and osteoclast markers. Data were analysed by nonparametric statistics.

Results: In co-cultures of macrophages and osteoblasts, pressure modulated secretion of sRANKL or OPG in a variable manner. Examination of the OPG:sRANKL ratio in co cultures without pressurisation showed that the ratio was greater in donors $<70$ years at the time of operation ( $P$ $<0.05$ Mann Whitney $U$ ) than it was in patients $>70$ years. However, with pressure the difference in the OPG:sRANKL ratios between young and old donors was not significant. It was striking that in some patients the OPG:sRANKL ratio increased with pressure whereas in some it decreased. The tendency was for the ratio to decrease with pressure in patients younger than 70 years, and increase in patients $\geq 70$ years (Fishers exact $p<0.01$ ).

Cultures of osteoblasts alone showed a significant increase in both SRANKL and OPG with pressure, and again there was a decrease in the ratio of OPG:RANKL. Secretion of sRANKL by cultures of macrophages alone was not modulated by pressure. Only sRANKL was assayed in this study, but transmembrane RANKL may also be important in this system. Macrophages subjected to pressure (both alone and in co-culture) stained more strongly for RANK on immunohistochemstry than non-pressurized controls and I,25-dihydroxyvitamin $D_{3}\left(\begin{array}{lll}1,25 & D_{3}\end{array}\right)$ further increased this. Immunocytochemical staining also demonstrated that more cells in 
pressurized co-cultures exhibited osteoclast markers (tartrate-resistant acid phosphatase, vitronectin receptor and multinuclearity) than did unpressurized controls.

Conclusion: These data show that in co-cultures of osteoblasts and macrophages the ratio of OPG : sRANKL was decreased by pressure in younger patients but increased in older patients. As falls in this ratio promote bone resorption, this finding may be important in explaining the relatively high incidence of osteolysis around orthopaedic implants in young patients. The finding that secretion of OPG and sRANKL by osteoblasts in monoculture was sensitive to hydrostatic pressure, and that hydrostatic pressure stimulated the differentiation of macrophages into cells exhibiting osteoclast markers indicates that both osteoblasts and preosteoclasts are sensitive to cyclic pressure. However, the effects of pressure on cocultures were not simply additive and coculture appears useful to examine the interaction of these cell types.

These findings have implications for future therapies for aseptic loosening and for the development of tests to predict the development of this condition.

\section{Background}

The effect of strain on bone is now well documented [1-3] and it is clear that increased strain generally leads to increased bone formation. A few studies have examined the effect of hydrostatic compression on bone or bone cells [4-10] and similarly found that hydrostatic compression is likely to lead to increased net bone formation. Both cancellous and cortical bone has a structure of multiple interconnected spaces and there is evidence that applied strain leads to changes in intraosseous pressure. It is possible that, biologically speaking, cyclic hydrostatic pressure may be more influential than strain in a dense structural tissue such as bone.

Aseptic loosening and associated bone loss is the commonest complication of orthopaedic implants. Most studies have concentrated on the role of wear particles and the subsequent invasion of the joint space by activated macrophages [11]. Research has shown that elevated hydrostatic pressures develop in aseptic loosening and there is increasing evidence that this may contribute to loosening and macrophage activation [12-18]. The activated macrophages are responsible for the increased bone resorption seen in aseptic loosening, and several studies have demonstrated that they are able to differentiate into osteoclasts [19-22]. There has been debate about whether, in vivo, macrophage rich membranes are responsible for bone resorption per se, or whether this is only performed by osteoclasts which are in turn activated by products of the macrophage. The actual importance of this distinction for possible treatment of aseptic loosening is unclear.

Previous studies in our laboratory demonstrated that cyclical hydrostatic pressure increased macrophage synthesis of several cytokines [23,24], of macrophage-colony stimulating factor (M-CSF), chemokines and prostaglandin E2 [25]. These molecules are known to be important in bone resorption and turnover and in osteoclastogene- sis, but the mechanisms by which they exert their effects in vivo (especially in relation to implant loosening) are still poorly understood. In addition, we have shown that cyclical hydrostatic pressure increased macrophage-mediated bone resorption in bone organ cultures [24].

The three molecules, RANK, RANKL and OPG, have now been shown to be pivotal to bone homeostasis [26]. They are intimately involved in osteoclastogenesis [27-30] and studies have shown that alterations to the ratio of OPG:RANKL affect bone turnover [31-33]. We therefore examined the effect of cyclical hydrostatic pressure on secretion of OPG, RANKL and RANK by human macrophages and osteoblasts in vitro. In addition, as these molecules are important in the modulation of osteoclastogenesis, the effect of cyclical hydrostatic pressure on the phenotype of the macrophage was also investigated.

\section{Methods \\ Co-cultures of macrophages and osteoblasts}

For co-cultures, $50 \mathrm{mls}$ of blood was taken from donor patients 6 weeks after primary hip replacement. Monocytes were isolated using Lymphoprep density gradient medium (Apogent Discoveries UK) as described previously [23]. An average of $11.3 \times 10^{6}$ monocytes were isolated per sample. Briefly, peripheral blood mononuclear cells were suspended in Minimum Essential Medium (MEM) and placed in a tissue culture flask (Nunc) for one hour at $37^{\circ} \mathrm{C}$ with $5 \% \mathrm{CO}_{2}$. Monocytes were separated from the rest of the cell population by adherence. After removal of non-adherent cells, the adherent cells were scraped off using a cell scraper and resuspended in culture medium (MEM, 20\% foetal calf serum (FCS), 1\% Penicillin / Streptomycin, 1\% Glutamate). Cell numbers were counted and used in the experiments as described below. 
Osteoblasts were isolated from human trabecular bone using the explant technique, as described previously [34] using bone samples removed during elective surgery for primary hip replacement. Osteoblasts were seeded onto slices of dentine ( $100 \mu \mathrm{m}$ thick, $4.0 \mathrm{~mm}$ diameter), at $5 \times$ $10^{5}$ cells $/ \mathrm{ml}\left(1 \times 10^{5}\right.$ per slice $)$ and placed in 96-well plates (Corning UK) before culturing overnight in Dulbecco's modified Eagles medium (DMEM, Invitrogen UK) supplemented with $20 \%$ foetal calf serum (FCS, Invitrogen UK). Human macrophages were then seeded onto the osteoblast layer at a density of $5 \times 10^{5}$ cells $/ \mathrm{ml}\left(1 \times 10^{5}\right.$ cells per slice) and the co-cultures were incubated for a further six days in DMEM supplemented with $20 \%$ foetal calf serum, $1 \%$ glutamine (Invitrogen UK), $30 \mathrm{ng} / \mathrm{ml} \mathrm{M-CSF},(\mathrm{R}+\mathrm{D}$ Systems UK), 10-8 M Dexamethasone (Sigma UK) and 10${ }^{7} \mathrm{M} 1,25 \mathrm{D}_{3}$ (Sigma UK). Three replicate wells per treatment were set up for each experiment and both cell types were from the same donor. Informed consent was obtained from patients before samples were taken for this research, and the study was approved by the Salford LREC.

The co-cultures were subjected to $34.5 \times 10^{-3} \mathrm{MPa}(5 \mathrm{psi})$ cyclical hydrostatic pressure ( 2 secs on, 2 secs off) for one hour for 4 consecutive days in our unique pressurization apparatus [23], in a $5 \% \mathrm{CO}_{2}$ /balance air environment (B.O.C. Special Gases Ltd UK). Cultures were allowed to rest for 23 hours after pressurization before media were harvested for assay and stored at $-20^{\circ} \mathrm{C}$ before assaying for OPG and sRANKL. Cells on the dentine were stained to determine cell type.

\section{Culture of macrophages}

Monocytes were prepared as above, from normal blood or blood from patients prior to primary hip replacement, prior to use in the following experiment.

Human macrophages were seeded onto slices of dentine at $5 \times 10^{5}$ cells $/ \mathrm{ml}\left(1 \times 10^{5}\right.$ cells per slice $)$ before culturing for a further six days in DMEM supplemented with $20 \%$ FCS, $1 \%$ glutamine, $30 \mathrm{ng} / \mathrm{ml} \mathrm{M-CSF}, 10^{-8} \mathrm{M}$ Dexamethasone and $10^{-7} \mathrm{M} 1,25 \mathrm{D}_{3}$. Three replicate wells per treatment were set up for each experiment.

The cultures were subjected to $34.5 \times 10^{-3} \mathrm{MPa}(5 \mathrm{psi})$ cyclical hydrostatic pressure ( 2 secs on, 2 secs off) for one hour for 4 consecutive days. Cultures were allowed to rest for 23 hours after pressurization before media were harvested for assay and stored at $-20^{\circ} \mathrm{C}$ before assaying for OPG and sRANKL.

\section{Culture of osteoblasts}

Osteoblasts isolated for the co-cultures were also cultured without macrophages. Cells were seeded onto slices of dentine at a cell density of $5 \times 10^{5}$ cells $/ \mathrm{ml}\left(1 \times 10^{5}\right.$ per slice) and cultured as above for 6 days before subjecting them to pressure (see above). Cultures were allowed to rest for 23 hours after pressurization before media were harvested and stored at $-20^{\circ} \mathrm{C}$ before assaying for OPG and sRANKL.

For all co-culture/macrophage/osteoblast experiments, control cultures (i.e. not subjected to hydrostatic pressure) were included.

\section{Effect of hydrostatic pressure on OPG and sRANKL secretion}

Culture media were assayed directly for sRANKL using a specific ELISA kit (Peprotech EC - human sRANKL ELISA development kit), according to the manufacturers directions. Culture media was assayed for OPG using an inhouse ELISA method [35]. A goat anti-human OPG antibody was used (R+D Systems UK) to coat the ELISA plates (Appleton Woods UK). The standard curve consisted of dilutions of recombinant human OPG (Alexis Corp.). A biotinylated goat anti-human OPG antibody ( $\mathrm{R}+\mathrm{D}$ Systems UK) was used with ExtraAvidin peroxidase (Sigma UK) to amplify the signal. OPG binding was visualised using TMB (Pierce Chemical Co.) and optical densities determined at $450 \mathrm{~nm}$. Inter- and intra- assay variation was $12.8 \%$ and $7.7 \%$ respectively and specificity was confirmed by recovery experiments using heparin-affinity purified human OPG.

For all these experiments, control cultures (i.e. not subjected to hydrostatic pressure) were included.

\section{Effect of $I, 25$ dihydroxyvitamin $D_{3}$ on RANK production by macrophages}

Monocytes were isolated as described previously [23] from normal blood or blood from patients prior to primary hip replacement. The macrophages thus obtained were cultured as before [23] prior to use in the experiments outlined below. Macrophages were cultured at $5 \times$ $10^{5} / \mathrm{ml}$ on Thermanox coverslips (Nunc, UK) in 24-well plates (Corning UK) and incubated in DMEM with 20\% FCS and $1 \%$ glutamine, for 7 days. $1,25 \mathrm{D}_{3}$ was added to the cultures at either $10^{-7} \mathrm{M}$ or $10^{-9} \mathrm{M}$ one hour before cultures were pressurised at $34.5 \times 10^{-3} \mathrm{MPa}$ ( $5.0 \mathrm{psi}$ ), ( 2 secs on, 2 secs off) for one hour [23]. To examine whether the effect of pressure was additive, some cultures were subjected to one cycle of pressure $(1 \times 1$ hour $)$ and others to four cycles (the four cycles being performed on consecutive days). Cultures were allowed to rest for 23 hours after pressurization before macrophages were fixed in $100 \%$ ice-cold ethanol (BDH, UK) for two minutes.

Cell cultures were immunostained for RANK with a specific polyclonal antibody to RANK (Santa Cruz Biotechnology, USA; RANK C-20). Briefly, cells were incubated overnight at $4{ }^{\circ} \mathrm{C}$ with anti-RANK $(1 / 100)$ and positive 
staining disclosed using the $\mathrm{ABC}$ technique (Vectastain, UK). Control slides were incubated with $1 \%$ non-immune serum (Normal horse serum; Vectastain) to check antibody specificity. All slides were stained at the same time to minimise variation in staining intensity.

\section{Effect of hydrostatic pressure on osteoclast markers}

Monocytes were isolated as described previously [25] from the venous blood of healthy volunteers. The macrophages thus obtained were cultured as before [25] prior to use in the experiment outlined below. Macrophages were cultured at $5 \times 10^{5} / \mathrm{ml}$ on Thermanox coverslips (Nunc, UK) in 24-well plates and incubated in DMEM, 20\% FCS, $1 \%$ Glutamine, supplemented with $30 \mathrm{ng} / \mathrm{ml} \mathrm{M-CSF,} 10^{-}$ ${ }^{8} \mathrm{M}$ Dexamethasone, $30 \mathrm{ng} / \mathrm{ml}$ sRANKL and $10^{-7} \mathrm{M}$ $1,25 \mathrm{D}_{3}$, for 7 days. Cultures were then subjected to hydrostatic pressure at $34.5 \times 10^{-3} \mathrm{MPa}(5.0 \mathrm{psi})$ ( 2 secs on, 2 secs off) for one hour.

To examine whether the effect of pressure was additive, cultures were subjected to either one or four cycles of pressure (the four cycles being performed on consecutive days). Cultures were allowed to rest for 23 hours after pressurization before media were harvested and frozen at $-20^{\circ} \mathrm{C}$. Macrophages were fixed in $100 \%$ ice-cold ethanol (BDH, UK) for 2 minutes and stored at $-20^{\circ} \mathrm{C}$.

Cells were stained for tartrate-resistant acid phosphatase (TRAP) using a commercial kit (Sigma Cat. No.387-A), to demonstrate enzyme activity and multinuclearity. Cells were also immunostained for the vitronectin receptor (VNR) with a specific monoclonal antibody to VNR (Serotech; Cat. No MCA7576). Briefly, cells were incubated overnight at $4{ }^{\circ} \mathrm{C}$ with anti-VNR (1/100) and positive staining disclosed using the ABC technique (Vectastain, UK). Control slides were incubated with $1 \%$ non-immune serum (Normal horse serum; Vectastain) to check antibody specificity.

For all these experiments, control cultures (i.e. not subjected to hydrostatic pressure) of cells from the same population were included.

Table I: The effect of pressure on secretion of sRANKL and OPG by macrophages and osteoblasts cultured alone or in co-culture

\begin{tabular}{llll}
\hline & $\begin{array}{l}\text { Co-cultures of } \\
\text { MP \& OB }\end{array}$ & OB & MP \\
& & & \\
SRANKL (pg/ml) & & & \\
+ P & $672 \pm 180$ & $703 \pm 118$ & $264 \pm 39$ \\
- P & $878 \pm 193$ & $421 \pm 61$ & $270 \pm 45$ \\
OPG (ng/ml) & & & \\
+ P & $9.7 \pm 2.7$ & $23.6 \pm 4.2$ & 0 \\
- P & $8.1 \pm 1.75$ & $12.5 \pm 4.3$ & 0 \\
\hline
\end{tabular}

Table 2: The effect of pressure on ratio of OPG : sRANKLis influenced by the age of the donor

\begin{tabular}{ccccr}
\hline Patient & Age & $\begin{array}{c}\text { OPG: sRANKL } \\
-\mathbf{P}\end{array}$ & $\begin{array}{c}\text { OPG: sRANKL } \\
\mathbf{+} \mathbf{P}\end{array}$ & $+\mathbf{P}:-\mathbf{P}$ \\
\hline MK & 40.97 & 8.38 & 0 & 0 \\
AH & 53.76 & 20.6 & 19.4 & 0.941748 \\
MM & 57.06 & 6.2 & $1 \mathrm{I}$ & 1.774194 \\
SS & 59.41 & 150 & 25 & 0.166667 \\
CW & 64.33 & 42.2 & 17.8 & 0.421801 \\
SR & 65.5 & 53.7 & 59.2 & 1.102321 \\
DH & 65.72 & 15.4 & 19.5 & 1.266234 \\
SC & 72.44 & 6.59 & 9.46 & 1.435508 \\
KN & 72.76 & 11.28 & 22.1 & 1.95922 \\
JR & 75.38 & 3 & 18 & 6 \\
MI & 77.58 & 12.9 & 30 & 2.325581 \\
LM & 81.5 & 5.6 & 20 & 3.571429 \\
GB & 81.61 & 3.24 & 3.92 & 1.209877 \\
& & & & \\
\hline
\end{tabular}

\section{Statistical analysis}

Statistical analysis was performed on the data, where relevant. To demonstrate the effect of pressure, Friedmanns non-parametric two-way ANOVA followed by the Wilcoxon Signed Ranks Test was used. To demonstrate significance between different age groups, Mann Whitney U and Fishers Exact Test was used.

\section{Results \\ Effect of hydrostatic pressure on OPG and sRANKL secretion \\ Effect on co-cultures of macrophages and osteoblasts:}

Initial analysis of the data, where the results from individual patients were pooled, suggested that pressure did not modulate secretion of sRANKL and OPG by co-cultures

Table 3: The effect of age on direction of change of OPG:sRANKL with pressure. $\Downarrow$ cases decreased the OPG:sRANKL ratio with cyclic pressure, while $\Uparrow$ cases increased the ratio

\begin{tabular}{|c|c|c|}
\hline$<65$ (mean 55 y) & $\geq 65$ (mean 74 y) & $\mathrm{P}<0.0$ I Fishers exact test \\
\hline 4 & 0 & \\
\hline$\Downarrow$ & & \\
\hline I & 8 & \\
\hline
\end{tabular}

Osteoblasts were seeded onto slices of dentine at $5 \times 10^{5} \mathrm{cells} / \mathrm{ml}$, placed in 96-well plates and cultured overnight. Macrophages were seeded onto the osteoblast layer at $5 \times 10^{5} \mathrm{cell} / \mathrm{s} / \mathrm{ml}$ and cultured for a further six days in DMEM supplemented with M-CSF $(30 \mathrm{ng} / \mathrm{ml})$, Dexamethasone $\left(10^{-8} \mathrm{M}\right)$ and $1,25 \mathrm{D}_{3}\left(10^{-7} \mathrm{M}\right)$. Three replicate wells per treatment were set up for each experiment and both cell types were from the same donor. The effect of pressure ("P") and age on secretion of sRANKL and OPG was compared using the Mann Whitney $U$ test.

(Table 1). 
However, calculation of the ratios of OPG:sRANKL for individual patients showed an increase with pressure in some samples and a decrease in others (Table 2). Examination of the effect of donor age showed that the unpressurised OPG:sRANKL ratio was lower in samples from patients over 70 years (Mann Whitney $U \mathrm{p}<0.05$ ). (Table 2.) The application of pressure resulted in this difference becoming much less evident $(\mathrm{p}=0.94)$. The difference between OPG:sRANKL (with pressure) and (without pressure) was smaller or negative in patients $<70$ years (Mann Whitney $U \mathrm{p}<0.05$ ) (Table 3). Pressure was more likely to cause an increase in the ratio in patients of 65 or over, and a decrease in younger patients $(\mathrm{p}<0.01$ Fishers exact test).

Effects on monocultures of osteoblasts:

For osteoblasts (from the same cell population) cultured without macrophages, pressure modulated secretion of both sRANKL and OPG. Pressure increased secretion of sRANKL by $73 \%$ and this increase was statistically significant ( $p=0.002)$ (Wilcoxon Signed Ranks test); OPG secretion was increased by $89 \%$ and this increase was statistically significant $(p=0.034)$ (Wilcoxon Signed Ranks test) (Table 1). No change in the ratio of OPG:sRANKL was detected with pressure $(65.2 \pm 69.2$ [no pressure] and $43.7 \pm 42.6$ [with pressure]).

Effects on monocultures of macrophages:

Pressure had no effect on secretion of sRANKL by macrophages cultured without osteoblasts (Table 1) $(\mathrm{p}=0.69)$ (Wilcoxon Signed Ranks test) and OPG was not detectable in most of these cultures.

It was noticeable that basal secretion of sRANKL in the monocultures was substantially reduced and that basal secretion of OPG increased, compared with the co-cultures (Table 1). The application of pressure to the cultures increased the total secretion of sRANKL in the osteoblast monocultures to that seen in the co-cultures, but this was not seen in the macrophage monocultures. It is notable that pressure increased total OPG secretion by monocultures of osteoblasts to above that seen in the pressurized co-cultures (Table 1).

\section{Effect of hydrostatic pressure on RANK in macrophage cultures}

Macrophages cultured without pressure (controls) synthesised RANK (Fig 1) and, subjectively speaking, cultures exposed to pressure (Fig 1a.) appeared to be stained more intensely for RANK than controls (Fig 1b). This synthesis was further modulated when macrophages were incubated with $1,25 \mathrm{D}_{3}$, as RANK staining was more intense in cultures incubated with $10^{-7} \mathrm{M}$ (Fig 1c.) compared to the (a)

(b)

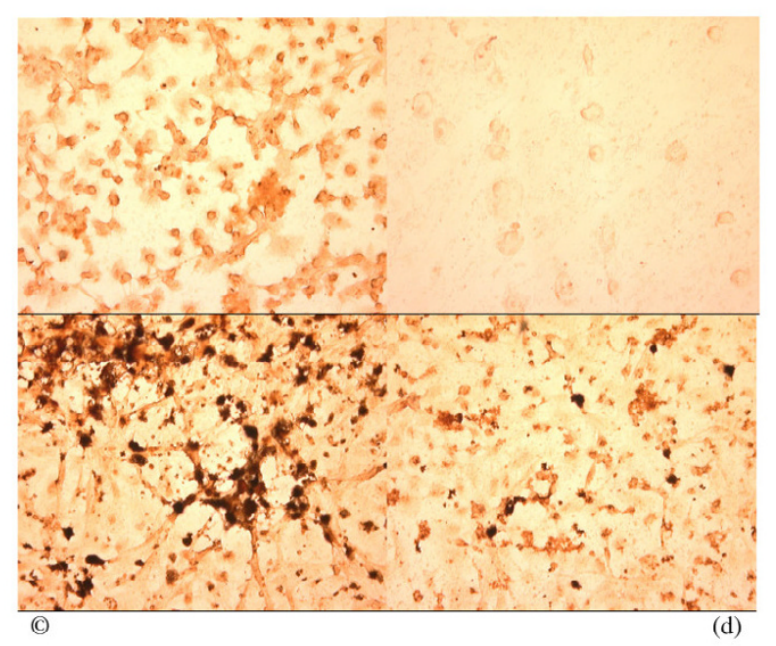

\section{Figure I}

Effect of hydrostatic pressure and I,25D $D_{3}$ on synthesis of RANK by cultured human macrophages. Macrophages were cultured at $5 \times 10^{5} /$ well for 7 days. I, $25 \mathrm{D}_{3}\left(10^{-}\right.$ $7 \mathrm{M}$ or $10^{-9} \mathrm{M}$ ) was added and cultures were subjected to one cycle of pressure $\left(34.5 \times 10^{-3} \mathrm{MPa}\right)$. Macrophages were immunostained for RANK with a specific polyclonal antibody. Cells exposed to pressure and $10^{-7} \mathrm{M} I, 25 \mathrm{D}_{3}$ (a) synthesised more RANK than cells exposed to pressure and 10-9M $1,25 D_{3}$ (b). Cultures supplemented with $I, 25 D_{3}$ synthesised more RANK than control cultures without $1,25 \mathrm{D}_{3}$ (c). MP in pressurised synthesised more RANK than in control cultures without pressure (d).

lower concentration, $10^{-9} \mathrm{M}$ (Fig 1d.). Even without pressure, staining was more intense in macrophages cultured with $1,25 D_{3}$ (Fig 2a,b) than those cultured without (Fig 2c.) and again staining was more intense in with $10^{-7} \mathrm{M}$ (Fig 2a.) compared to $10^{-9} \mathrm{M}$ (Fig 2b.).

Cyclical hydrostatic pressure appeared to have a cumulative effect on RANK synthesis, with staining appearing more intense in cultures exposed to four cycles of pressure (Fig 3.), compared to those only exposed to one cycle (Fig 1.). In addition, RANK staining was more intense in pressurized cultures (Fig 3a-c) compared to static controls (Fig $3 \mathrm{~d}-\mathrm{g}$ ), regardless of the addition of $1,25 \mathrm{D}_{3}$. Again, RANK staining was more intense in macrophages incubated with $1,25 \mathrm{D}_{3}$ (Fig 3a,b) than control cultures (Fig 3c) and staining intensity was greater in cultures exposed to the higher level of $1,25 \mathrm{D}_{3}, 10^{-7} \mathrm{M}$, compared to $10^{-9} \mathrm{M}$ $(3 a, b$.$) .$

The intensity of the RANK immunostaining was semiquantified by grading from a score of no positively stained 


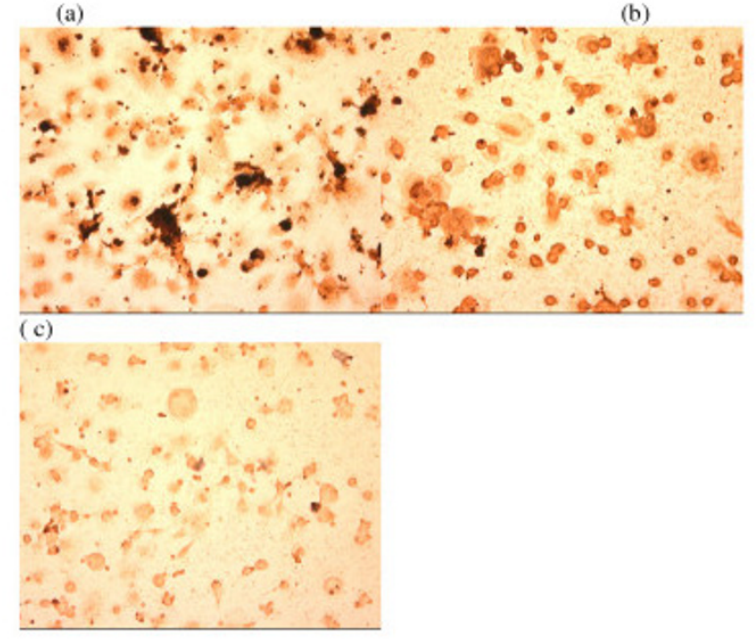

Figure 2

Effect of $I, 25 D_{3}$ alone on synthesis of RANK by cultured human macrophages. Macrophages were cultured at $5 \times 10^{5} /$ well for 7 days. I,25 $\mathrm{D}_{3}\left(10^{-7} \mathrm{M}\right.$ or 10-9 M) was added. Macrophages were immunostained for RANK with a specific polyclonal antibody. Cells exposed to $10^{-7} \mathrm{M} I, 25 \mathrm{D}_{3}$ (a) synthesised more RANK than cells exposed to 10-9 M I, $25 D_{3}$ (b). Cultures supplemented with $I, 25 D_{3}$ synthesised more RANK than control cultures without $\mathrm{I}_{2} 25 \mathrm{D}_{3}(\mathrm{c})$.

cells (-), some positively stained cells (+/-), to all cells positively and densely stained (+++) (Table 3.).

\section{Effect of hydrostatic pressure on OC markers}

The number of TRAP positive cells was increased in cultures exposed to cyclical hydrostatic pressure (Figure 4a) compared to static controls (b). In addition, although only a small proportion of the cells were multinucleated, there were more multinucleated cells in pressurized cultures (Fig 4c) compared to controls (Fig 4d).

The total number of TRAP positive and TRAP negative cells per culture was counted using a light microscope (Vickers) and a $\times 20$ objective. Exposure to cyclical pressure produced a larger number of TRAP positive cells compared to the static control cultures. The mean number of TRAP positive cells in pressurized cultures was $173 \pm 86$ (SD) compared to only $128 \pm 88$ (SD) in non-pressurized cultures. These results are calculated from cell counts from 5 separate experiments, with three replicate wells per experiment $(n=15)$. Statistical analysis demonstrated that the increase was highly statistically significant (Wilcoxon Signed Ranks Test; $\mathrm{p}<0.0001$ ). The percentage of TRAP positive cells in pressurized cells compared to static controls (Fig 5) was statistically significantly different (Wilcoxon Signed Ranks Test; $\mathrm{p}=0.026$ ). The percentage



(b)

(d)
Figure 3

Cumulative effect of pressure on synthesis of RANK by cultured human macrophages. Macrophages were cultured at $5 \times 105 /$ well for 7 days. I,25D $\left(10^{-7} \mathrm{M}\right.$ or $\left.10^{-9} \mathrm{M}\right)$ was added and cultures were subjected to four cycles of pressure $\left(34.5 \times 10^{-3} \mathrm{MPa}\right)$. Macrophages were immunostained for RANK with a specific polyclonal antibody. Cells exposed to pressure and 10-7M I,25 $\mathrm{D}_{3}$ (a) synthesised more RANK than cells exposed to pressure and $10^{-9} \mathrm{M} I, 25 \mathrm{D}_{3}(\mathrm{~b})$. Cultures supplemented with I,25D $\mathrm{D}_{3}$ synthesised more RANK than control cultures without I,25D $\mathrm{D}_{3}$ (c). Pressurised MP synthesised more RANK than control cultures without pressure (d). In unpressurized cultures, MP synthesis of RANK

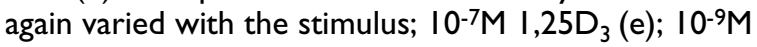
$\mathrm{I}, 25 \mathrm{D}_{3}(\mathrm{f}) ;$ no $\mathrm{I}, 25 \mathrm{D}_{3}(\mathrm{~g})$.

increase in the number of TRAP positive cells induced by pressure was variable however, with increases within the range $9-88 \%$, with a mean increase of $28 \pm 12$ (SD).

Immunostaining cultures for the VNR demonstrated that the number of VNR positive cells was also increased by pressure (Fig 6a) compared to controls (6b).

\section{Discussion}

Three molecules, OPG, RANKL and RANK, play a vital role in controlling bone homeostasis [26]. Osteoclastogenesis is initiated and maintained by at least two key 


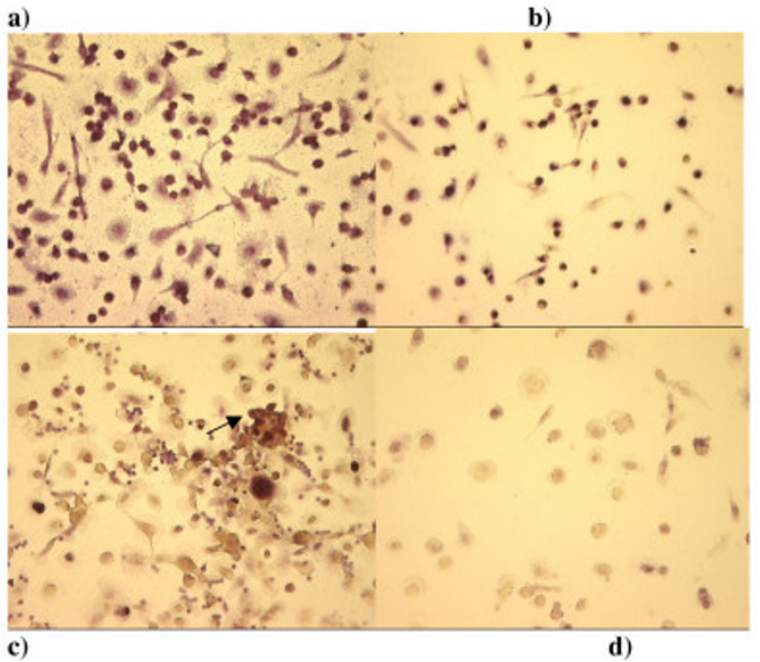

\section{Figure 4}

Effect of hydrostatic pressure on the number of TRAP positive and multinucleated cells. MP $\left(5 \times 10^{5 /}\right.$ $\mathrm{ml}$ ) from healthy volunteers were cultured at $5 \times 10^{5}$ cells $/ \mathrm{ml}$ on Thermanox coverslips in supplemented medium for 7 days before pressurisation $\left(34.5 \times 10^{-3} \mathrm{MPa}\right)(5.0 \mathrm{psi})$ for four cycles of pressure. MP were fixed and stained for TRAP; a) with pressure; b) without pressure. More multinucleated cells (arrows) were seen with pressure c) than without d).

factors produced locally in bone, M-CSF and RANKL. RANKL is found both as a transmembrane molecule on osteoblasts, which also secrete OPG, and as a secreted molecule, sRANKL. OPG opposes RANKL and blocks osteoclastogenesis. RANK is found on osteoclast-like cells and mononuclear cells in bone [33] and other tissues [36,37]. The balance between OPG, RANKL and RANK is crucial to bone homeostasis [38] as the ratio between OPG and RANKL modulates osteoclast activity and has been shown to vary during bone turnover [31-33,39]. Increases in OPG:RANKL would be expected to favour bone formation, and decreases to favour resorption.

To date, only a handful of studies have addressed the role of RANKL in aseptic loosening [40-42], whilst the importance of OPG has only recently been examined in this context [43]. The response to mechanical load vis a vis RANKL and OPG is variable. Strain has been shown to increase expression of RANKL mRNA in rat periodontal ligaments in vivo [44]. In vitro, strain had no effect on synthesis of RANKL protein by periodontal ligament cells [45] although OPG expression was increased [45]. Bone stromal cells respond differently to strain, which decreased RANKL mRNA in one study [46] and increased it in another [47]. To the authors' knowledge, no studies to



\section{Figure 5}

Effect of hydrostatic pressure on the percentage of TRAP positive cells. MP $\left(5 \times 10^{5} / \mathrm{ml}\right)$ from healthy volunteers were cultured at $5 \times 10^{5}$ cells $/ \mathrm{ml}$ on Thermanox coverslips in supplemented medium for 7 days before pressurisation $\left(34.5 \times 10^{-3} \mathrm{MPa}\right)(5.0 \mathrm{psi})$ for four cycles of pressure. MP were fixed and stained for TRAP. For each sample, the number of positive and negative cells in 5 random microscope fields was counted, for each of three replicates. Results are the mean and SD of 5 separate experiments.

date have examined the effect of hydrostatic pressure on OPG or sRANKL in macrophages or osteoblasts.

The results reported here demonstrate that in cocultures of osteoblasts and macrophages from the same donor patient, the OPG:sRANKL ratio is affected both by age and by cyclic pressure. Without pressure, young patients $(<70$ years at operation) had higher OPG:sRANKL ratios. The effect of pressure on this was different in young and old patients, with young patients tending to show a fall in OPG:sRANKL and older patients showing a rise. After application of pressure there was no longer a significant difference between patients above and below 70 years.

Other groups have found a correlation between age and changes in the ratio of RANKL:OPG [31]. Most patient studies have demonstrated an increase in circulating OPG with age [48-51] together with a decrease in sRANKL $[48,51]$. Conversely, an in vitro study using murine bone marrow cells co-cultured with pre-osteoclasts demonstrated that, although osteoclastogenesis increased with age, the levels of RANKL mRNA increased whilst mRNA for OPG decreased [52]. It is of interest that several pathologies have been linked to alterations in OPG and RANKL. The ratio of RANKL:OPG was increased in bone from elderly fracture patients $[53,54]$ and low levels of RANKL have been suggested as a predictor of fracture [55]. 


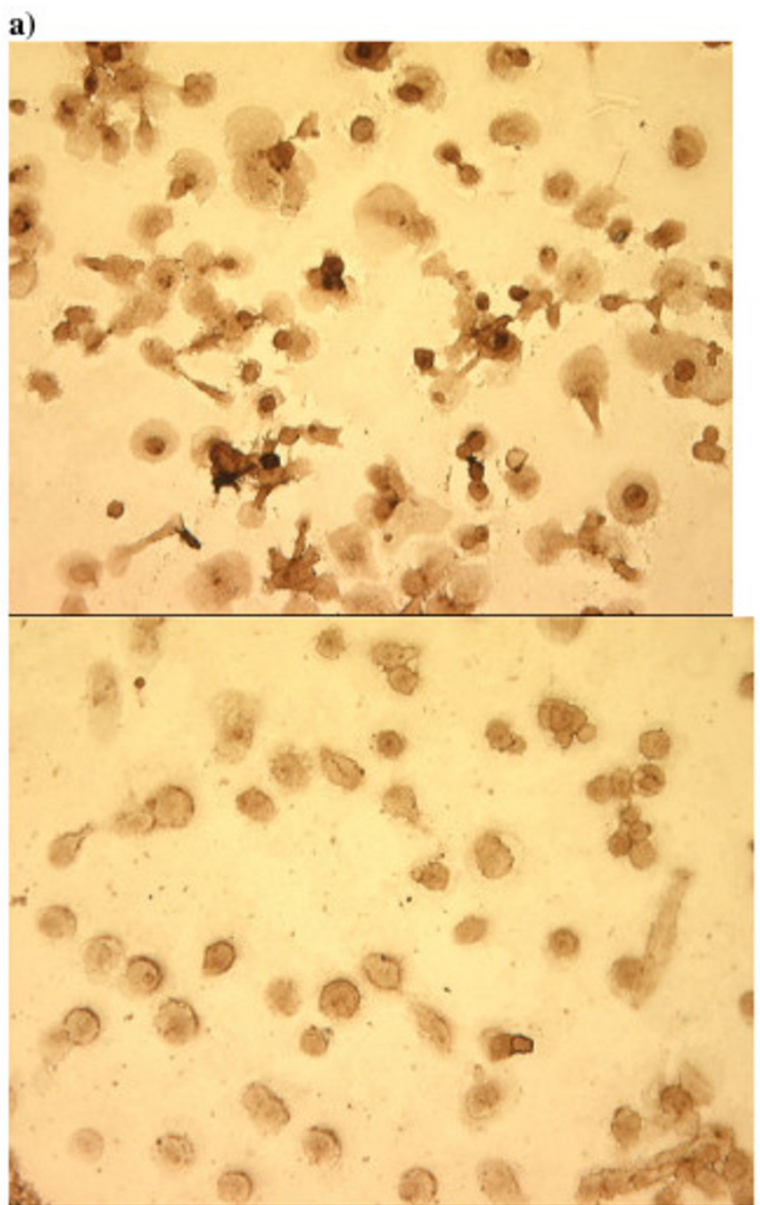

b)

\section{Figure 6}

Effect of hydrostatic pressure on the number of VNR positive cells. MP $\left(5 \times 10^{5} / \mathrm{ml}\right)$ from healthy volunteers were cultured at $5 \times 10^{5}$ cells $/ \mathrm{ml}$ on Thermanox coverslips in supplemented medium for 7 days before pressurisation (34.5 $\left.\times 10^{-3} \mathrm{MPa}\right)(5.0 \mathrm{psi})$ for four cycles of pressure. MP were fixed and immunostained for the VNR; a) with pressure; b) without pressure.

In addition, in patients with rheumatoid arthritis, RANKL polymorphisms were associated with an earlier age of disease onset [56].

The finding that the effect of pressure on OPG:sRANKL in cocultures was different in young and old patients was unexpected. Young patients, who would normally be expected to have a bone forming response to activity (and hence to changes in intraosseous pressure), proved to often have a fall of OPG:sRANKL with pressure. This may be because our co-culture setup has a high ratio of macrophages (osteoclast precursors) to osteoblasts. The differ- ing secretion of the mediators in monoculture and coculture strongly suggest that the relative numbers of macrophages and osteoblasts will influence the OPG:sRANKL ratio. The setup of the co-cultures was designed to model the bone/membrane interface of a loosening membrane, and it is likely that it does not correspond to a normal bone surface. The proportions of macrophages and osteoblasts are more similar to the loosening membrane situation than to the surface of a normal piece of bone. The change in the effect of cyclic pressure with age may help explain why results of hip replacements are consistently better in older people (Swedish Hip Register 2003). This has previously been attributed to reduction in levels of activity (and hence implant wear) with age, but our findings indicate that young patients may be biologically more susceptible to the development of osteolysis and bone resorption in this situation. This finding may have value in developing tests predictive of implant loosening in young patients.

In osteoblasts cultured alone, secretion of both sRANKL and OPG was significantly increased under pressure and the mean ratio of OPG:sRANKL was decreased $49 \%$ in osteoblast monoculture. Pressure had no effect on secretion of sRANKL by MP monoculture and these cells secreted no detectable OPG. There is a theoretical possibility that, in these cultures, complexes may form between OPG and sRANKL. Whilst we know that TRAIL and RANKL inhibit the OPG assay (personal communication) no data is available on binding to such complexes for the sRANKL assay kit.

Comparison between co cultures and monocultures of detectable product (sRANKL or OPG) and of the mean ratio of OPG:sRANKL suggests a feedback mechanism could be operating between these two cell types in vitro and that pressure modulates this cell-cell communication. Active osteoblastic activity has previously been reported at the bone surface adjacent to loosening membranes [57], and, as our data demonstrated that pressure affected the ratio between OPG and sRANKL it is tempting to speculate that a similar effect may be produced in the in vivo situation. This suggested scenario does not take into account the contribution of transmembrane RANKL, which, for technical reasons, was not assayed in this study.

In addition, immunostaining of MP for RANK showed a clear increase in RANK after pressurization, compared to controls. In addition, the effect of pressure on RANK synthesis was cumulative, as RANK synthesis was increased when the number of loading cycles was increased. It is of interest that RANK synthesis was also increased when MP were cultured with $1,25 \mathrm{D}_{3}$ (a factor strongly implicated in bone resorption) [58], as we have shown that pressure increases synthesis of $1,25 \mathrm{D}_{3}$ by MP [59]. Other studies 
Table 4: Synthesis of RANK by human macrophages is modulated by both hydrostatic pressure and I,25-dihydroxy vitamin $D_{3}$

\begin{tabular}{|c|c|c|c|c|c|c|}
\hline \multirow{2}{*}{$\begin{array}{l}\text { No. Cycles/ } \\
\text { Experiment } \\
\text { period (days) }\end{array}$} & \multicolumn{3}{|c|}{ No Pressure } & \multicolumn{3}{|c|}{ Plus Pressure } \\
\hline & $-D_{3}$ & $+D_{3}(10-9 M)$ & $+D_{3}(10-7 M)$ & $-D_{3}$ & $+D_{3}(10-9 M)$ & $+D_{3}(10-7 M)$ \\
\hline I & $-/+$ & + & $+/++$ & + & $+/++$ & ++ \\
\hline 4 & + & $+/++$ & ++ & + & ++ & +++ \\
\hline
\end{tabular}

MP were cultured as described in text and and cultures were scored for the proportion of RANK-positive cells, where "+/-" is some positive cells, "+" all positive cells, "+/++"all positive cells \& staining more intense and "+++" is the most intense staining. Results are the means from separate experiments.

have also shown that $1,25 \mathrm{D}_{3}$ increased RANK expression in MP [60]. In addition, expression of RANK has been shown to be elevated in peri-implant tissue in aseptic loosening, aiding osteoclast differentiation [40] and, as RANK demonstrates a autoregulatory positive feedback system, this could further enhance osteoclast differentiation in this tissue [60].

Cyclical hydrostatic pressure also modulated other markers on monocultures of human MP, moving them towards an osteoclast-like phenotype. After exposure to five sets of cyclical pressure, the majority of cells were positive for both TRAP and VNR. To our knowledge, this is the first time that cyclical hydrostatic pressure has been shown to influence MP differentiation in isolated MP. Others [61] have demonstrated that static compression inhibited osteoclast formation, but these studies were done using mouse marrow, where a mixed cell population was present and therefore no direct comparison can be made.

Other stimuli linked to osteoclastogenesis $\left(1,25 \mathrm{D}_{3}\right.$, RANKL or osteoblasts themselves) increased the number of positive cells for these markers, when compared to controls. Exposure to the additional stimulus of hydrostatic pressure further increased the numbers of positive cells. However, very few multinucleated cells were visible, indicating that cell fusion, the end-stage of osteoclast differentiation, was not stimulated by pressure over the time scale of these studies.

\section{Conclusion}

An age-related difference in the ratio of OPG:sRANKL was found in co-cultures of osteoblasts and macrophages and cyclic hydrostatic pressure modulated this ratio, causing a reduction in younger patients. In monocultures, pressure increased OPG:sRANKL secretion by osteoblasts and RANK synthesis by macrophages. The macrophage phenotype was also modulated, generating osteoclast-like cells. In summary, pressure modulates cell activity, disturbing homeostasis and favouring osteolysis; the balance of the system differs between young and old patients.

\section{Competing interests}

The author(s) declare that they have no competing interests.

\section{Authors' contributions}

CEE conceived and designed the study in conjunction with JGA. JGA provided the clinical samples. CEE ran the study overall, interpreted the data, performed statistical analyses and drafted the manuscript. JGA also performed statistical analyses and helped with interpretation of data and helped with drafting the manuscript. SM carried out all the tissue culture, performed all the assays, analysed the data, coordinated the study and contributed to the manuscript.

\section{Acknowledgements}

This project was funded by the British Orthopaedic Research Association (Wishbone Trust). The funding was made possible by Kirby Laing Foundation, The George Livanos Trust, The Eleanor Peel Charitable Trust, The PF Trust and The Garfield Weston Foundation. We are also grateful to Dr M Marshall of the Charles Salt and Agnes Hunt Research Centre, Oswestry, UK, for his advice on OPG and time in performing the OPG assays.

\section{References}

I. Granet C, Guignandon A, Vico L, Alexandre C, Lafage-Proust M-H: MAP and src kinases control the induction of AP-I members in response to changes in mechanical environment in osteoblastic cells. Cellular Signalling 2002, 14:679-88.

2. Kaspar D, Seidl W, Neidlinger-Wilke C, Beck A, Claes L, Ignatius A: Proliferation of human-derived osteoblast-like cells depends on the cycle number and frequency of uni-axial strain. J Biomech 2002, 35:873-880.

3. Skerry TM: Identification of novel signalling pathways during functional adaptation of the skeleton to mechanical loading: the role of glutamate as a paracrine signalling agent in the skeleton. J Bone Min Res 1999, 17:66-70.

4. Klein-Nulend J, Veldhuijzen JP, de Jong M, Burger EH: Increased bone formation and decreased bone resorption in fetal mouse calvaria as a result of intermittent compressive force in vitro. Bone Min 1987, 2(6):44I-8.

5. Roelofsen J, Klein-Nulend J, Burger EH: Mechanical stimulation by intermittent hydrostatic compression promotes bone-specific gene expression in vitro. J Biomech 1995, 28: | 493-503.

6. Glantschnig H, Varga F, Rumpler M, Klaushofer K: Prostacyclin (PGI2): a potential mediator of c-fos expression induced by hydrostatic pressure in oreoblastic cells. J Clin Invest 1996, 26:544-8.

7. Nagatomi, Arulanandam BP, Metzger DW, Meunier A, Bizios R: Frequency- and duration-dependent effects of cyclic pressure on select bone cell functions. Tissue Eng 200I, 7:717-728. 
8. Nagatomi , Arulanandam BP, Metzger DW, Meunier A, Bizios R. Cyclic pressure affects osteoblast functions pertinent to osteogenesis. Ann Biomed Eng 2003, 3 I:917-923.

9. Takai E, Mauck RL, Hung CT, Guo XE: Osteocyte viability and regulation of osteoblast function in a 3D trabecular bone explant under dynamic hydrostatic pressure. J Bone Min Res 2004, 19:1403-10.

10. Tasevski V, Sorbetti JM, Chiu SS, Shrive NG, Hart DA: Influence of mechanical signals on gene expression in human MG-63 cells: evidence for a complex interplay between hydrostatic compression and vitamin D3 or TGF $\beta-I$ on MMP-I and MMP-3 mRNA levels. Biochem Cell Biol 2005, 83:96-107.

II. McGee MA, Howie DW, Costi K, Haynes DR, Wildenaur Cl, Pearcy MJ, McLean JD: Implant retrieval studies of the wear and loosening of prosthetic joints: a review. Wear 2000, 24I:I58-65.

12. Hendrix RW, Wixson RL, Rana NA, Rogers IF: Arthrography after Total Hip Arthroplasty; a Modified Technique used in the Diagnosis of Pain. Radiology 1983, I48:647-652.

13. Anthony PP, Gie GA, Howie CR, Ling RSM: Localised Endosteal Bone Lysis in Relation to the Femoral Components of Cemented Total Hip Arthroplasty. J Bone Joint Surg (Br) 1990, 72:971-979.

14. Robertsson $\mathrm{O}$, Wingsterand $\mathrm{H}$, Kesteris $\mathrm{U}$, Jonsson $\mathrm{K}$, Onnerfalt R: Intracapsular pressure and loosening of hip prostheses. Acta Orthop Scand 1997, 68:231-234.

15. Aspenberg $\mathrm{P}, \mathrm{Van}$ der $\mathrm{Vis} \mathrm{H}$ : Fluid pressure may cause periprosthetic osteolysis: particle are not the only thing. Acta Orthop Scand 1998, 69:1.

16. Skoglund B, Aspenberg P: PMMA particles and pressure - a study of the osteolytic properties of two agents proposed to cause prosthetic loosening. J Orthop Res 2003, 2 I : |96-20|

17. Schmalzried TP, Guttmann D, Grecula M, Amstutz HC: The relationship between the design, position and articular wear of acetabular components inserted without cement and the development of pelvic osteolysis. J Bone Joint Surg Am 1995, 77: $1290-1$

18. Yuan X, Ryd L, Huiskes R: Wear particle diffusion and tissue differentiation in TKA implant fibrous interfaces. J Biomech 2000, 33: $1279-86$

19. Matsuzaki K, Udagawa N, Takahashi N, Yamaguchi K, Yasuda H, Shima N, Morinaga T, Toyama Y, Yabe Y, Higashio K, Suda T: Osteoclast differentiation factor (ODF) induces osteoclast-like cell formation in human peripheral blood mononuclear cel cultures. Biochem Biophys Res Comm 1998, 246:199-204.

20. Quinn JMW, Neale S, Fujikawa $Y$, McGee JOD, Athanasou NA: Human osteoclast formation from blood monocytes, peritoneal macrophages and bone marrow cells. Calcif Tiss Int 1998, 62(6):527-31.

21. Haynes DR, Crotti TN, Potter AE, Loric M, Atkins GJ, Howie DW, Findlay DM: The osteoclastogenic molecules RANKL an RANK are associated with periprosthetic osteolysis. J Bone Joint Res 2001, 83-B:902-91I.

22. Lader C, Scopes J, Horton M, Flanagan AM: Generation of human osteoclasts in stromal cell-free and stromal cell-rich cultures: differences in osteoclasts CDIIc/CDI8 integrin expression. Br J Haematol 200 I, I I 2:430-437.

23. Ferrier GM, McEvoy A, Evans CE, Andrew JG: The effect of cyclical pressure on human monocyte-derived macrophages in vitro. J Bone Joint Surg 2000, 82-B:755-9.

24. McEvoy A, Jeyam M, Ferrier G, Evans CE, Andrew JG: Synergistic effect of particles and cyclic pressure on cytokine production in human monocyte/macrophages : Proposed role in periprosthetic osteolysis. Bone 2002, 30/1:171-I77.

25. Sampathkumar S, Evans CE, Andrew JG: Role of cyclical pressure in release of $M-C S F$, chemokines and $P G_{2}$ and their role in implant loosening. J Bone Joint Surg 2003, 85-B(2):288-9I.

26. Khosla S: The OPG/RANKL/RANK system. Endocrinology 200I, | 42:5050-5055

27. Chambers TJ, Owens JM, Hattersley G, Jat PS, Noble MD: Generation of osteoclast-inductive and osteoclastogenic cell-lines form the H-2K(B)TSA58 transgenic mouse. PNAS 1993, 90:5578-82

28. Suda T, Udagawa N, Nakamura I, Miyaura C, Takahashi N: Modulation of osteoclast differentiation by local factors. Bone 1995, | 7(2):S87-S9|.
29. Simonet WS, Lacey DL, Dunstan CR, Kelley M, Chang MS, Luthy R, Nguyen HQ, Wooden S, Bennett L, Boone T, Shimamoto G, DeRose M, Elliott R, Colombero A, Tan HL, Trail G, Sullivan J, Davy E, Bucay N, Renshaw, Gegg L, Hughes TM, Hill D, Pattison W, Campbell P, Sander S, Van G, Tarpley J, Derby P, Lee R, Boyle WJ: Osteoprotegerin: A novel secreted protein involved in the regulation of bone density. CELL 1997, 89(2):309-319.

30. Yasuda H, Shima N, Nakagawa N, Yamaguchi K, Kinosaki M, Mochizuki S, Tomoyasu A, Yano K, Goto M, Murakami A, Tsuda E, Morinaga T, Higashio K, Udagawa N, Takahashi N, Suda T: Osteoclast differentiation factor is a ligand for osteoprotegerin osteoclastogenesis-inhibitory factor and is identical to TRANCE/ RANKL. PNAS 1998, 95(7):3597-3602.

31. Fazzalari NL, Kuliwaba JS, Atkins GJ, Forwood MR, Findlay DM: The ratio of messenger RNA levels of receptor activator of nuclear kappaB ligand to osteoprotegerin correlates with bone remodeling indices in normal human cancellous bone but not in osteoarthritis. I Bone Min Res 2001, 16:1015-27.

32. Giuliani N, Bataille R, Mancini C, Lazzaretti M, Barille S: Myeloma cells induce imbalance in the osteoprotegerin/osteoprotegerin ligand system in the human bone marrow environment. Blood 200I, 98:3527-33.

33. Ikeda T, Utsuyama M, Hirokawa K: Expression profiles of receptor activator of nuclear factor kappaB ligand, receptor activator of nuclear factor kappaB, and osteoprotegerin messenger RNA in aged and ovariectomized rat bones. Bone Min Res 200I, I6:1416-25.

34. Evans CE, Galasko CSB, Ward C: Effect of donor age on the growth in vitro of cells obtained from human trabecular bone. J Orthop Res 1990, 8(2):234-237.

35. O'Brien EA, Williams JHH, Marshall MJ: OPG is produced when prostaglandin synthesis is inhibited causing osteoclasts to detach from the surface of mouse parietal bone and attach to the endocranial membrane. Bone 200I, 28(2):208-2I4.

36. Komura H, Olee T, Kuhn K, Quach J, Brinson DC, Shikhman A, Valbracht J, Creighton-Achermann L, Lotz M: The osteoprotegerin/ receptor activator of nuclear factor ka-paB ligand system in cartilage. Arthritis \& Rheumatism 200I, 44:2768-76.

37. Dodds RA, Ali N, Pead MJ, Lanyon LE: Early loading-related changes in the activity of glucose 6-phosphate dehydrogenase and alkaline phosphatase in osteocytes and periosteal osteoblasts in rat fibulae in vivo. J Bone Min Res 1993, 8:26I-7.

38. Hofbauer LC, Khosla S, Dunstan CR, Lacey DL, Boyle WJ, Riggs BL: The roles of osteoprotegerin and osteoprotegerin ligand in the paracrine regulation of bone resorption. I Bone Min Res 2000, I 5:2-12.

39. Crisafulli A, Altavilla D, Squadrito G, Romeo A, Adamo EB, Marini R, Inferrera Marini H, Bitto A, D'Anna R, Corrado F, Bartolone S, Frisina $\mathrm{N}$, Squadrito $\mathrm{F}$ : Effects of the phytoestrogen genistein on the circulating soluble receptor activator of nuclear factor kappa B ligand-osteoprotegerin system in early postmenopausal women. Journal of Clinical Endocrinology and Metabolism 2004, 89:188-192

40. Crotti TN, Smith MD, Weedon H, Capone M, Holding C, Findlay DM, Haynes DR: Osteoprotegerin (OPG) and RANKL expression in tissues near bone in diseases of pathological bone loss: A comparison of rheumatoid arthritis, prosthetic joint failure and periodontal disease. J Bone Min Res 2001, I 6:S227-S227.

4I. Mandelin J, Li TF, Lijestrom M, Hanemaaijer R, Santavirta S, Konttinen YT: Imbalance of RANKL/RANK/OPG system in interface tissue in loosening of total hip replacement. J Bone joint Surg 2003, 85-B: II96-1201.

42. Crotti TN, Smith MD, Findlay DM, Zreiqat H, Ahern MJ, Weedon H, Hatzinilolous G, Capone M, Holding C, Haynes DR: Factors regulating osteoclast formation in human tissues adjacent to peri-implant bone loss: expression of receptor activator NF kappa $\beta$, RANK ligand and osteoprotegerin. Biomaterials 2004 , 25(4):565-73

43. Gehrke T, Sers C, Morawietz L, Fernahl G, Neidel J, Frommelt L, Krenn V: Receptor activation of nuclear kappa $B$ ligand is expressed in resident and inflammatory cells in aseptic and septic prosthesis loosening. Scand J Rheumatol 2003, 32(5):287-4.

44. Kaku M, Uoshima K, Yanashita Y, Miura H: Investigation of periodontal ligament reaction upon excessive occlusal load - osteopontin induction among periodontal ligament cells. Periodontal Res 2005, 40:59-66. 
45. Tsuji K, Uno K, Zhang GX, Tamura M: Periodontal ligament cells under intermittent stress regulate mRNA expression of osteoprotegerin and tissue inhibitor of matrix metalloprotease-I and -2. Bone Min Res 2004, 22(2):94-103.

46. Rubin J, Murphy TC, Fan X, Goldschmidt M, Taylor WR: Activation of extracellular signal-regulated kinase is involved in mechanical strain inhibition of RANKL expression in bone stromal cells. J Bone Min Res 2002, I 7(8): I 452-60.

47. MacQuarrie RA, Chen YF, Coles C, Anderson Gl: Wear-particleinduced osteoclast osteolysis : The role of particulates and mechanical strain. J Biomed Mater Res 2004, 69B: 104-I I 2.

48. Trofimov S, Pantsulaia I, Kobyliansky E, Livshits G: Circulating levels of receptor activator of nuclear factor-kappa B ligand/ osteoprotegerin/macrophage-colony stimulating factor in a presumably healthy human population. Eur J Endocrinol 2004, I50:305-3II.

49. Pulsatelli L, Dolzani P, Silvestri T, Caraceni P, Facchini A, Ravaglia G, Salvarani C, Meliconi R, Mariani E: Soluble receptor activator of nuclear factor-kappa B ligand (sRANKL)/osteoprotegerin balance in ageing and age-associated diseases. Biogerentology 2004, 5: I19-127.

50. Franck H, Meurer T, Hofbauer LC: Evaluation of bone mineral density, hormones, biochemical markers of bone metabolism, and osteoprotegerin serum levels in patients with Ankylosing spondylitis. J Rheumatol 2004, 3 I:2236-4I.

5I. Abrahamsen B, Hjelmborg J, Kostenuik P, Stilgren LS, Kyvik K, Adamu S, Brixen K, Langdahl BL: Circulating amounts of osteoprotegerin and RANK ligand: Genetic influence and relationship with BMD assessed in female twins. Bone 2005, 36:727-35.

52. Cao JJ, Wronski T, Iwaniec U, Phleger L, Kurimoto P, Boudignon B, Halloran BP: Aging increases stromal/osteoblastic cell-induced osteoclastogenesis and alters the osteoclast precursor pool in the mouse. J Bone Min Res 2005, 20:1659-68.

53. Abdallah BM, Stilgren LS, Nissen N, Kassem M, Jorgensen HRI, Abrahamsen B: Increased RANKL/OPG mRNA ratio in iliac bone biopsies from women with hip fractures. Calcified Tissue Int 2005, 76:90-97.

54. Tsangari H, Findlay DM, Kuliwaba JS, Atkins GJ, Fazzalari NL: Increased expression of IL-6 and RANK mRNA in human trabecular bone from fragility fracture of the femoral neck. Bone 2004, 35:334-42.

55. Schett G, Kiechl S, Redlich K, Oberhollenzer F, Weger S, Egger G Mayr A, Jocher J, Xu QB, Pietschmann P, Teitelbaum S, Smolen J, Willeit J: Soluble RANKL and risk of nontraumatic fracture. JAMA 2004, 291: I 108-13.

56. Wu H, Khanna D, Park G, Gersuk V, Nepom GT, Wong WK, Paulus HE, Tsao BP: Interaction between RANKL and HLA-DRB genotypes may contribute to younger age at onset of seropositive rheumatoid arthritis in an inception cohort. Arthritis and Rheum 2004, 50:3092-3103.

57. Atkins RM, Langkamer VG, Perry MJ, Elson CJ, Collins CMP: Bonemembrane interface in aseptic loosening of total joint arthroplasties. J Arthroplast 1997, I 2(4):46 I-4

58. Raisz LG, Trummel CL, Holick MF, DeLuca HF: I,25-dihydroxycholecalciferol: a potent stimulator of bone resorption in tissue culture. Science 1972, 175:768-9.

59. Evans CE, Mylchreest S, Mee A, Berry JA, Andrew : Hydrostatic Pressure Upregulates Vitamin $D_{3}$ Synthesis By Macrophages in vitro. Proceedings of International Conference on Progress in Bone and Mineral Research, Vienna, 2003.

60. Kido S, Inoue D, Hiura K, Javier W, Ito Y, Matsumoto T: Expression of RANK is dependent upon differentiation into the macrophage/osteoclast lineage: Induction by I alpha, 25-hydroxyvitamin $D_{3}$ and TPA in a human myelomonocytic cell line, HL60. Bone 2003, 32(6):62I-29.

61. Rubin J, Biskobing, Fan X, Rubin C, McLeod K, Taylor WR: Pressure regulates osteoclast formation and MCSF expression in marrow cultures. J Cellular Physiol 1997, 170:8I-7.

\section{Pre-publication history}

The pre-publication history for this paper can be accessed here:

http://www.biomedcentral.com/1471-2474/7/21/prepub
Publish with Bio Med Central and every scientist can read your work free of charge

"BioMed Central will be the most significant development for disseminating the results of biomedical research in our lifetime. "

Sir Paul Nurse, Cancer Research UK

Your research papers will be:

- available free of charge to the entire biomedical community

- peer reviewed and published immediately upon acceptance

- cited in PubMed and archived on PubMed Central

- yours - you keep the copyright
BioMedcentral 